\title{
Subacute mitral valve dysfunction after transcatheter aortic and mitral valve replacements
}

Anthony Poulin, MD, ${ }^{\mathrm{a}}$ Mathieu Bernier, MD, ${ }^{\mathrm{a}}$ Josep Rodes-Cabau, MD, ${ }^{\mathrm{a}}$ Daniel Doyle, MD, ${ }^{\mathrm{b}}$ and Jean-Michel Paradis, MD, ${ }^{\mathrm{a}}$ Québec, Quebec, Canada

\footnotetext{
From the Departments of ${ }^{\mathrm{a} C}$ Cardiology, and ${ }^{\mathrm{b}}$ Cardiovascular Surgery, Quebec Heart and Lung Institute, Québec, Quebec, Canada.

Disclosures: J.R.-C. holds the Canadian Research Chair "Fondation Famille Jacques Lariviere" for the Development of Structural Heart Disease Interventions and has received research grants from Edwards Lifesciences and Medtronic. All other authors have nothing to disclose with regard to commercial support.

Received for publication Oct 22, 2017; revisions received Dec 14, 2017; accepted for publication Dec 30, 2017; available ahead of print Feb 1, 2018

Address for reprints: Jean-Michel Paradis, MD, 2725 Chemin Sainte-Foy, Québec G1V 4G5, Quebec, Canada (E-mail: jean-michel.paradis@criucpq.ulaval.ca).

J Thorac Cardiovasc Surg 2018;155:e167-72

$0022-5223 / \$ 36.00$

Copyright (C) 2018 by The American Association for Thoracic Surgery
}

https://doi.org/10.1016/j.jtcvs.2017.12.118

Video clip is available online.

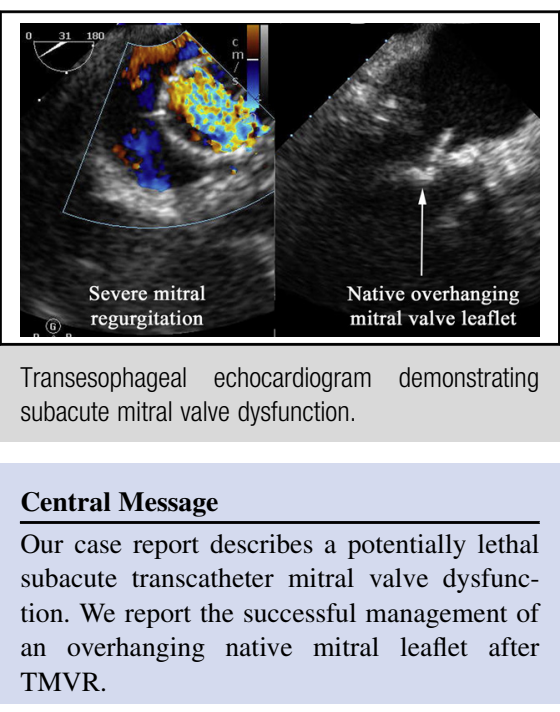

See Editorial Commentary page e173.
Severe aortic regurgitation is the indication to perform valve-in-valve implantation in almost all patients with previous transcatheter aortic valve replacement (TAVR), but few data are available on the incidence and mechanisms of acute severe central mitral regurgitation (MR) after transcatheter mitral valve replacement (TMVR). We report the occurrence of severe transcatheter heart valve (THV) leaflet malfunction after TMVR inside a calcified native mitral valve. An overhanging native mitral leaflet was seen, precluding appropriate closing of the THV. To our knowledge, this is the first description of an overhanging native mitral valve leaflet precluding proper function of a mitral THV implanted within a calcified native mitral valve.

\section{CLINICAL SUMMARY}

A 76-year-old woman with a history of previous surgical aortic valve replacement with a 21-mm Sorin Mitroflow prosthesis (Sorin Group Inc, Milan, Italy) and previous coronary artery bypass graft surgery was referred to our institution with severe shortness of breath (New York Heart Association functional class 4). Her medical history was also significant for hypertension, hyperlipidemia, type II diabetes mellitus, morbid obesity, and moderate chronic kidney disease (baseline creatinine clearance of $46 \mathrm{~mL} /$ min). Transesophageal echocardiography showed a left ventricular ejection fraction of $50 \%$, a left ventricular outflow tract diameter of $20 \mathrm{~mm}$, a failed aortic bioprosthesis (moderate to severe stenosis with peak and mean gradients of $47 \mathrm{~mm} \mathrm{Hg}$ and $22 \mathrm{~mm} \mathrm{Hg}$, respectively, combined with moderate regurgitation), severely calcified degenerative mitral stenosis (mitral valve area of $0.96 \mathrm{~cm}^{2}$, with peak and mean gradients of $22 \mathrm{~mm} \mathrm{Hg}$ and $8 \mathrm{~mm} \mathrm{Hg}$, respectively) and moderate degenerative mitral regurgitation (Figure $1, A$, and Video 1 ). The native anterior mitral valve leaflet was calcified, and its length was $22 \mathrm{~mm}$. Cardiac computed tomography revealed an aortic annular area of the bioprosthetic valve measured at $299 \mathrm{~mm}^{2}$ (stent internal diameter of $20.7 \times 18.2 \mathrm{~mm}$ and true theoretic internal diameter of $17.3 \mathrm{~mm}$; Figure 1, B). Cardiac computed tomography demonstrated a circumferential calcification of the native mitral annulus and a mitral annular area of $650 \mathrm{~mm}^{2}$ (mean diameter of $28.7 \mathrm{~mm}$; Figure 1, $C$ ). The patient was deemed not to be a surgical candidate by the heart team because of frailty and significant comorbidities (euroSCORE II of 47\%). Recent studies have shown the feasibility and effectiveness of transcatheter aortic valve-in-valve procedures ${ }^{1,2}$ as well as TMVR with balloon-expandable valves in patients with severe mitral annular calcification. ${ }^{3}$

\section{TECHNIQUE}

Our heart team, composed of cardiovascular surgeons, interventional cardiologists and echocardiographers, 


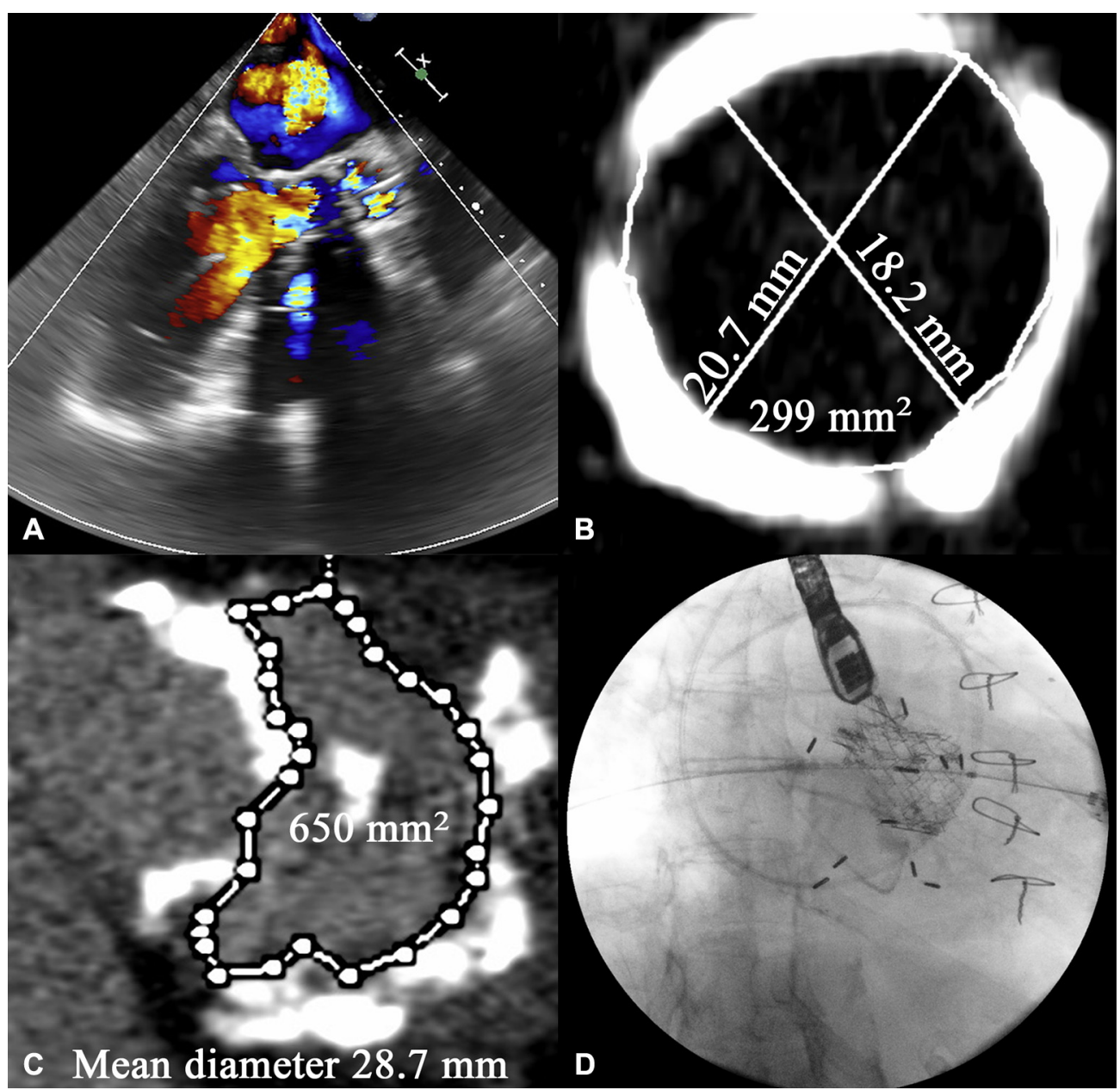

FIGURE 1. Transcatheter aortic valve-in-valve replacement and transcatheter mitral valve replacement. A, Severe aortic bioprosthesis stenosis and severe mitral disease demonstrated on transesophageal echocardiogram (Video 1). B and C, Cardiac computed tomography revealed a severely calcified aortic bioprosthetic valve with internal diameters of $18.2 \mathrm{~mm} \times 20.7 \mathrm{~mm}$ (area of $299 \mathrm{~mm}^{2}$; B) and circumferential calcification of the native mitral annulus (C). D, Deployment of a SAPIEN XT (Edwards Lifesciences, Irvine, Calif) 23-mm transcatheter heart valve in the aortic position (Video 2) and a SAPIEN XT 29-mm valve with marked dog-bone effect during inflation of the transcatheter heart valve in the mitral position (Video 3).

decided to proceed with concomitant valve-in-valve TAVR combined with TMVR through a transapical approach.

The patient was brought to our hybrid surgical room. A standard transapical access was obtained. Under transesophageal echocardiographic and fluoroscopic guidance, a SAPIEN XT 23-mm valve (Edwards Lifesciences, Irvine, Calif) was successfully deployed inside the Sorin Mitroflow 21-mm valve in the aortic position (postprocedural peak and mean gradients of 33 and $18 \mathrm{~mm} \mathrm{Hg}$; Video 2). Afterward, a stiff wire was placed across the mitral valve and positioned inside a pulmonary vein. A balloon valvuloplasty was performed. A SAPIEN XT 29-mm prosthesis was then firmly advanced across the very calcified native mitral valve. The deployment of the mitral transcatheter heart valve was done under rapid ventricular pacing. Moreover, to guide positioning, we used the dog-bone effect (Video 3) created by a very slow inflation of the balloon on which the THV was crimped (Figure 1, D, and Video 3).

Postprocedural transesophageal echocardiography showed mild to moderate paravalvular leak (Figure 2, A, and Video 4). There was no central MR, no significant gradient across the new THV, and no left ventricular outflow tract obstruction. The patient was subsequently transferred to the surgical intensive care unit. Three hours later, the patient developed severe cardiogenic shock as a result of a TMVR leaflet malfunction (Figure 2, B, and Video 5), leading to the new onset of severe central MR (Figure 2, $C$, and Videos 6 and 7). The heart team elected to proceed with an urgent mitral valve-in-valve replacement with another SAPIEN XT 29-mm prosthesis through the same transapical access (Figure 2, D, and Video 8). Immediate 


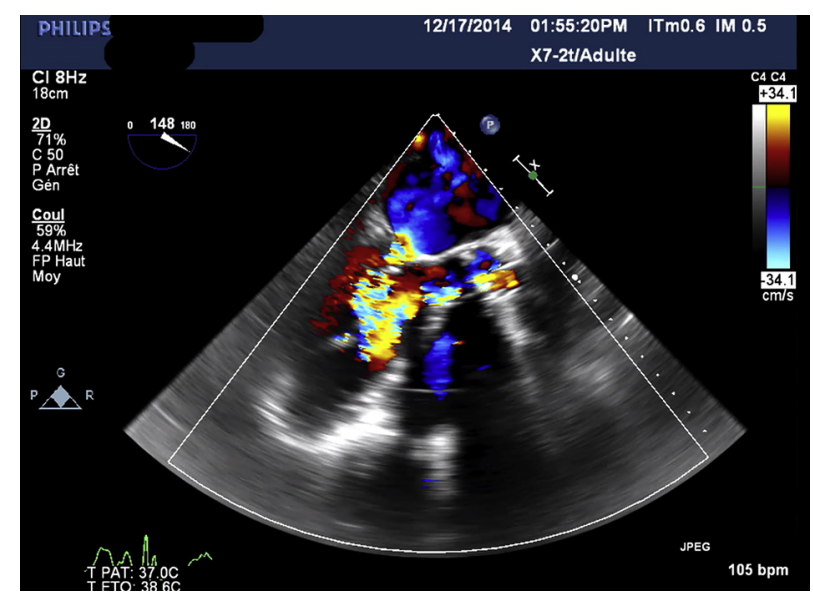

VIDEO 1. Transesophageal echocardiogram demonstrating severe aortic and mitral valve stenosis. Video available at: http://www.jtcvsonline.org/ article/S0022-5223(18)30037-0/fulltext.

resolution of the central MR (Video 9) led to major improvement of the hemodynamic parameters and weaning of vasopressors. Thirteen days later, cardiac magnetic resonance imaging was performed and showed mild to moderate paravalvular regurgitation without any central MR. Clinical progress was favorable, and the patient was discharged home on postoperative day 15.



VIDEO 2. Fluoroscopic imaging showing deployment of a SAPIEN XT (Edwards Lifesciences, Irvine, Calif) 23-mm transcatheter heart valve within a 21-mm Mitroflow (Sorin Group Inc, Milan, Italy) surgical bioprosthesis in the aortic position. Video available at: http://www. jtcvsonline.org/article/S0022-5223(18)30037-0/fulltext.



VIDEO 3. Fluoroscopic imaging showing deployment of a SAPIEN XT (Edwards Lifesciences, Irvine, Calif) $29-\mathrm{mm}$ valve transcatheter heart valve within the calcified native mitral valve. Video available at: http:// www.jtcvsonline.org/article/S0022-5223(18)30037-0/fulltext.

\section{DISCUSSION}

In patients with recently implanted aortic THV, severe aortic regurgitation is the indication to perform valve-invalve implantation in $97 \%$ of cases. ${ }^{4}$ Among those patients, the etiology of AR may be leaflet malfunction caused by calcium impingement, leaflet overhang, postdilation disruption of the architecture of the bioprosthesis, insufficient aortic pressure to close the leaflets of the TAVR, a tilted or canted valve, or aortic cusp rupture. ${ }^{5}$ In contrast, very sparse data are available on the incidence and the mechanisms of acute severe central MR after TMVR. We report the occurrence of severe THV leaflet malfunction after TMVR inside a calcified native mitral valve. In retrospect, an overhanging native mitral leaflet was seen to preclude the appropriate closing of the TMVR. This was probably caused by the relatively high auricular position of the first transcatheter mitral valve. Deployment of a second transcatheter valve in a more ventricular position resolved the acute mitral regurgitation by preventing protrusion of the calcified native anterior mitral leaflet underneath the mitral transcatheter valve. This demonstrates that valve positioning during TMVR is crucial to minimize the risk of left ventricular outflow tract obstruction, the risk of paravalvular leak, and possibly the risk of static or dynamic overhanging mitral leaflet. In our case, initial periprocedural success mitigates the possibility of a transcatheter leaflet damage or a disruption of the native mitral leaflets after balloon valvuloplasty. 




FIGURE 2. Overhanging native mitral valve leaflet and urgent transcatheter mitral valve-in-valve replacement. A, Mild to moderate paravalvular leak immediately after the procedure can be seen on transesophageal echocardiography (Video 4). B, Mitral transcatheter heart valve leaflet malfunction causing severe mitral regurgitation, leading to cardiogenic shock (Videos 5 and 6). C, Native overhanging mitral valve leaflet demonstrated on transesophageal echocardiogram (Video 7). D, Deployment of a SAPIEN XT (Edwards Lifesciences, Irvine, Calif) 29-mm valve in a more ventricular position (Video 8) led to immediate resolution of the central mitral regurgitation with favorable outcomes (Video 9).

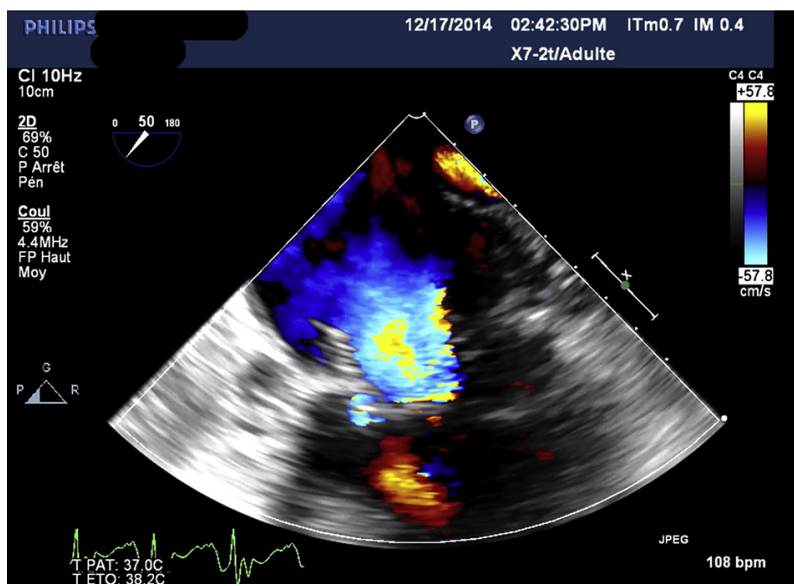

VIDEO 4. Transesophageal echocardiogram demonstrating mild to moderate paravalvular leak after the procedure. Video available at: http://www. jtcvsonline.org/article/S0022-5223(18)30037-0/fulltext.

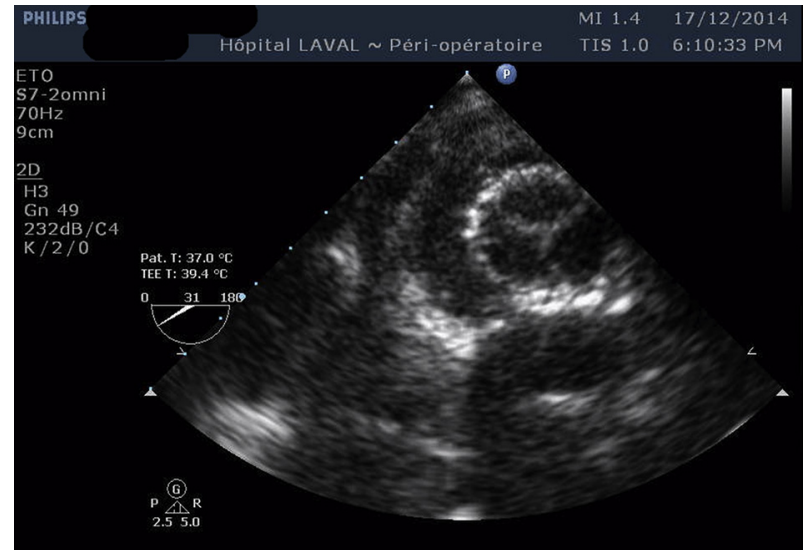

VIDEO 5. Transesophageal echocardiogram showing transcatheter mitral valve dysfunction. Video available at: http://www.jtcvsonline.org/article/ S0022-5223(18)30037-0/fulltext. 




VIDEO 6. Transesophageal echocardiogram with color Doppler showing severe central mitral regurgitation. Video available at: http://www.jtcvsonline. org/article/S0022-5223(18)30037-0/fulltext.

In summary, this case report is, to our knowledge, the first description of an overhanging native mitral valve leaflet precluding proper function of a mitral THV implanted within a calcified native mitral valve. Further studies will be needed to determine the nature, determinants, and outcomes of acute, subacute, and late THV malfunction after TMVR inside native mitral valves, as well as within failing mitral surgical bioprostheses and rings. In our

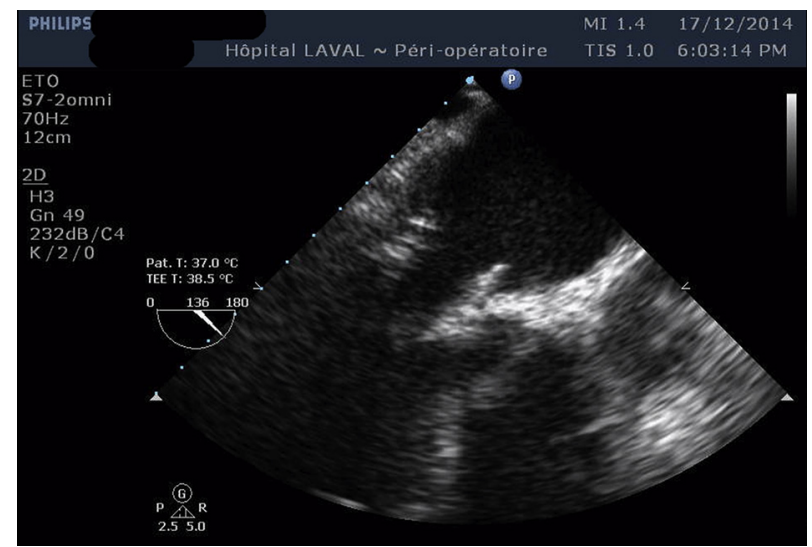

VIDEO 7. Transesophageal echocardiogram demonstrating a native overhanging mitral valve leaflet. Video available at: http://www.jtcvsonline. org/article/S0022-5223(18)30037-0/fulltext. opinion, this case illustrates the importance of case reports in advancing medical scientific knowledge of rare complications.

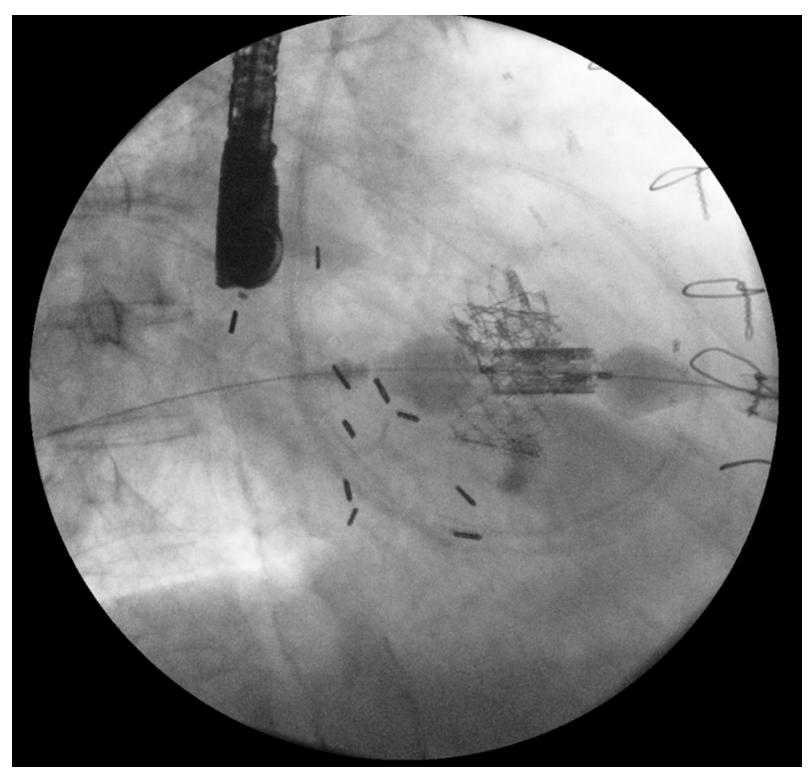

VIDEO 8. Fluoroscopic imaging showing deployment of a SAPIEN XT (Edwards Lifesciences, Irvine, Calif) $29-\mathrm{mm}$ valve in a more ventricular position. Video available at: http://www.jtcvsonline.org/article/S00225223(18)30037-0/fulltext. 


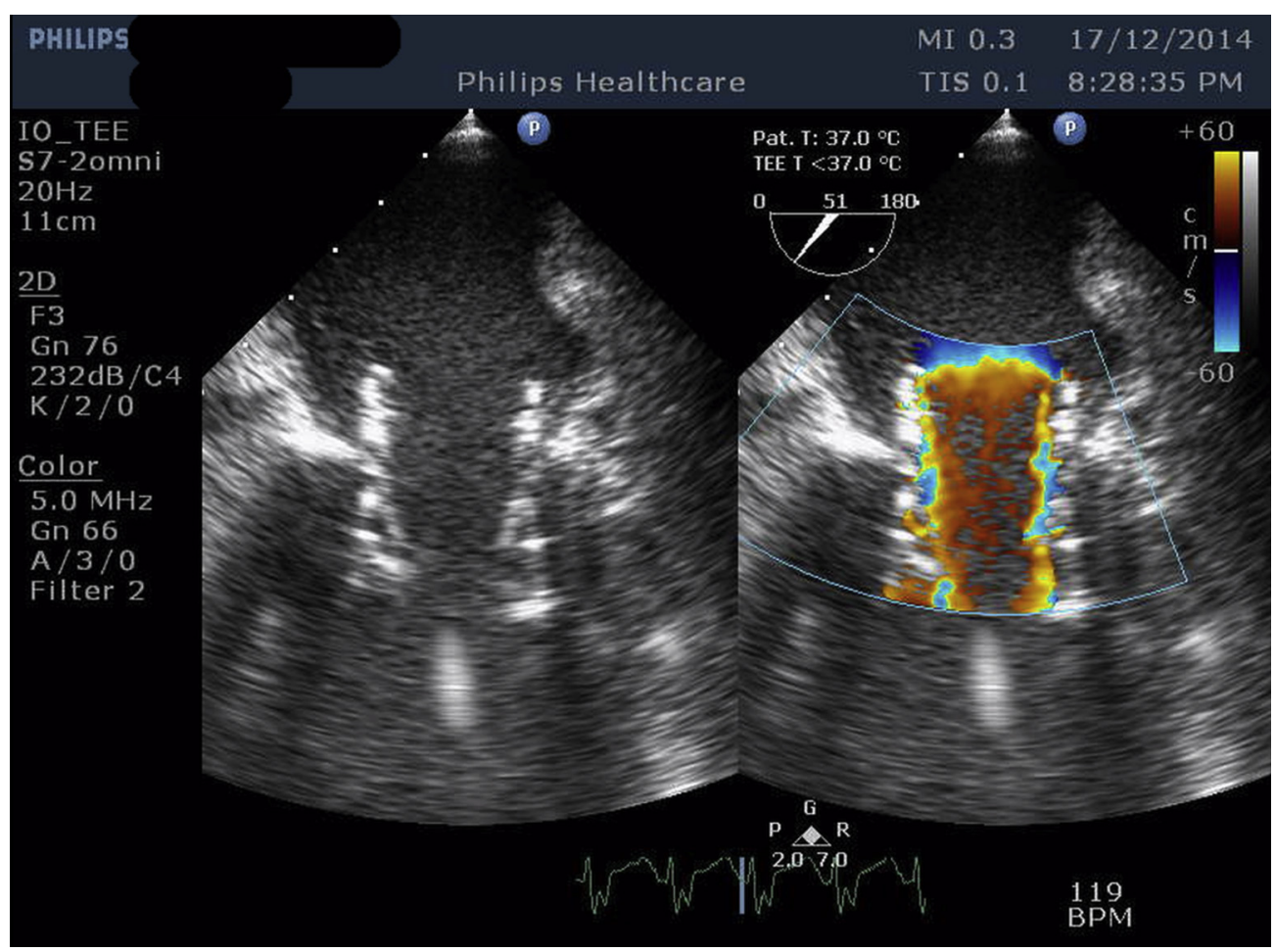

VIDEO 9. Transesophageal echocardiogram with color Doppler showing minimal mitral regurgitation after the mitral valve-in-valve procedure. Video available at: http://www.jtcvsonline.org/article/S0022-5223(18)30037-0/fulltext.

\section{References}

1. Webb JG, Mack MJ, White JM, Dvir D, Blanke P, Herrmann HC, et al. Transcatheter aortic valve implantation within degenerated aortic surgical bioprostheses: PARTNER 2 valve-in-valve registry. J Am Coll Cardiol. 2017;69: 2253-62.

2. Dvir D, Webb JG, Bleiziffer S, Pasic M, Waksman R, Kodali S, et al; Valve-inValve International Data Registry Investigators. Transcatheter aortic valve implantation in failed bioprosthetic surgical valves. JAMA. 2014;312:162-70.

3. Guerrero M, Dvir D, Himbert D, Urena M, Eleid M, Wang DD, et al. Transcatheter mitral valve replacement in native mitral valve disease with severe mitral annular calcification: results from the first multicenter global registry. JACC CardiovasC Interv. 2016;9:1361-71.

4. Makkar RR, Jilaihawi H, Chakravarty T, Fontana GP, Kapadia S, Babaliaros V, et al. Determinants and outcomes of acute transcatheter valve-in-valve therapy or embolization: a study of multiple valve implants in the U.S. PARTNER trial (Placement of AoRTic TraNscathetER Valve Trial Edwards SAPIEN Transcatheter Heart Valve). J Am Coll Cardiol. 2013;62:418-30.

5. Summers MR, Cremer PC, Jaber WA. Three mechanisms of early failure of transcatheter aortic valves: valve thrombosis, cusp rupture, and accelerated calcification. J Thorac Cardiovasc Surg. 2017;153:e87-93. 